\title{
Case Report: Molecular Detection of Dirofilaria repens in an Italian Patient after a Stay in Tanzania
}

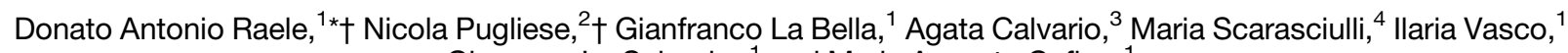 \\ Giovanna La Salandra, ${ }^{1}$ and Maria Assunta Cafiero ${ }^{1}$ \\ ${ }^{1}$ Istituto Zooprofilattico Sperimentale della Puglia e della Basilicata, Foggia, Italy; ${ }^{2}$ Dipartimento d Medicina Veterinaria, Università degli Studi di \\ Bari, Valenzano, Italy; ${ }^{3}$ Laboratorio di Virologia U.O.C. Microbiologia e Virologia AOU Policlinico, Bari, Italy; ${ }^{4}$ Laboratorio di Virologia U.O.C. \\ Microbiologia e Virologia, Dipartimento Interdisciplinare di Medicina, Università degli Studi di Bari, Valenzano, Italy
}

\begin{abstract}
A 35-year-old man was admitted to a hospital in the south of Italy because of a periocular nodule and subpalpebral edema. The patient reported having been stayed in Tanzania five months before. Hematologic parameters were within the normality range, the Acanthocheilonema viteae ELISA did not detect significant levels of antifilarial IgG, and no further symptoms were described. The surgical inspection of the nodule led to the isolation of two filarioid parasites, identified as Dirofilaria repens by scanning electron microscope (SEM), and then by molecular assays. Knott's test did not reveal microfilaremia, whereas loop-mediated isothermal amplification and PCR detected $D$. repens DNA. The patient was treated with doxycycline, and he was found no more positive at the follow-up.
\end{abstract}

\section{INTRODUCTION}

Human dirofilariasis by Dirofilaria (Nochtiella) repens (Nematoda, Onchocercidae) is a mosquito-borne parasitic zoonosis, which mostly affects dogs in the Old World. ${ }^{1,2}$ However, the disease is becoming a matter of growing concern because several factors, such as the frequent lack of clinical signs in both humans and dogs, the limited range of treatments, and the climate changes, are contributing to its wide circulation in Europe. ${ }^{3}$ In fact, an increasing number of reports are being recorded not only from Italy and other European countries bordering the Mediterranean Sea, where dirofilariasis is considered endemic, ${ }^{2,4}$ but also from Eastern Europe, in particular Russia and former Soviet countries, ${ }^{5}$ Northern Africa, and Middle and Far East. ${ }^{3}$

Microfilaremic domestic dogs are considered the most important Dirofilaria repens reservoir, despite wild dogs and cats being involved, too. ${ }^{4,6}$ Microfilariae produced by female worms may invade the bloodstream of the natural reservoir of the parasite and be ingested by mosquitoes, where they molt and develop into the infesting stage (larva L3), which, in turn, can be released or transmitted by bite to other hosts. ${ }^{7}$

In humans, dirofilariasis is often asymptomatic, and the parasite usually does not develop into the adult form, ${ }^{4}$ but larvae may spread through the bloodstream up to reach the subcutaneous tissues, often forming nodules. ${ }^{8}$

The golden standard for the diagnosis of canine or feline dirofilariasis is the Knott's test and its variants, ${ }^{9,10}$ based on the microscopic detection and morphological identification of microfilariae from blood. Considering that expert operators are needed to correctly recognize and identify microfilariae, molecular tests have been developed to selectively amplify by $\mathrm{PCR}^{11}$ and loop-mediated isothermal amplification (LAMP) ${ }^{12}$ species-specific regions of the $D$. repens genome. However, the intermittence of microfilaremia, along with the low concentration in blood, makes challenging the prompt diagnosis of dirofilariasis by $D$. repens in dogs. ${ }^{7}$ The issue is even more critical for humans because the

\footnotetext{
*Address correspondence to Donato Antonio Raele, Istituto Zooprofilattico Sperimentale della Puglia e della Basilicata, Via Manfredonia, 20, Foggia 71121, Italy. E-mail: donatoantonio.raele@izspb.it $\dagger$ These authors contributed equally to this work.
}

microfilarial stage is absent or, at least, very rare. ${ }^{13}$ In those cases, diagnosis may be achieved by combining anamnestic data (especially those about travels or lifestyle) and the clinical picture, with ultrasonography ${ }^{14}$ or morphometric examination. ${ }^{15}$

\section{CASE HISTORY}

In March 2019, a 35-year-old man, resident in Apulia, a region in the south of Italy, presented to a local hospital because of a subpalpebral edema surrounding a periocular nodule, about $1.5 \mathrm{~cm}^{2}$ large, localized under the left lower eyelid (Figure 1). The anamnestic record did not evidence relevant pathologic events, but the patient reported a two-week stay in Tanzania five months before the hospital admission. He also declared no further movements outside Apulia after having been returned to Italy.

The hematologic parameters were within the normality range, and the hemochromocytometric profile was regular (Table 1). A sample of serum underwent Acanthocheilonema vitae ELISA (Bordier Affinity Products, Crissier, Switzerland), a pan-filarial IgG-detecting immunoenzymatic assay, ${ }^{16}$ which returned a value of 0.46 , thus below the positivity threshold, established at 1.

The nodule was surgically inspected, and two adult filarial parasites, 10 and $5 \mathrm{~cm}$ long, respectively, were removed (Figure 2A). The SEM analysis of the specimens revealed morphological features compatible with $D$. repens, including longitudinal ridges on the external cuticle, typical of $D$. repens, ${ }^{17}$ Candidatus Dirofilaria hongkongensis, ${ }^{18}$ and Dirofilaria ursi, ${ }^{19}$ and two large lateral chords, considered $D$. repens specific (Figure 2B). ${ }^{17}$

The Knott's test resulted negative, but LAMP ${ }^{12}$ and $\mathrm{PCR}^{17}$ detected $D$. repens DNA from a specimen of blood EDTA. Total genomic DNA was also extracted and purified from a section of the removed worms and used as a template in the $\mathrm{PCR}^{17}$ to confirm the identification. The nucleotide sequences of the amplification products from blood (GenBank accession number MT683121) and worm (MT683122) were $100 \%$ identical between themselves, and one of them was aligned by ClustalO with a representative panel of corresponding sequences from $D$. repens present in GenBank. 


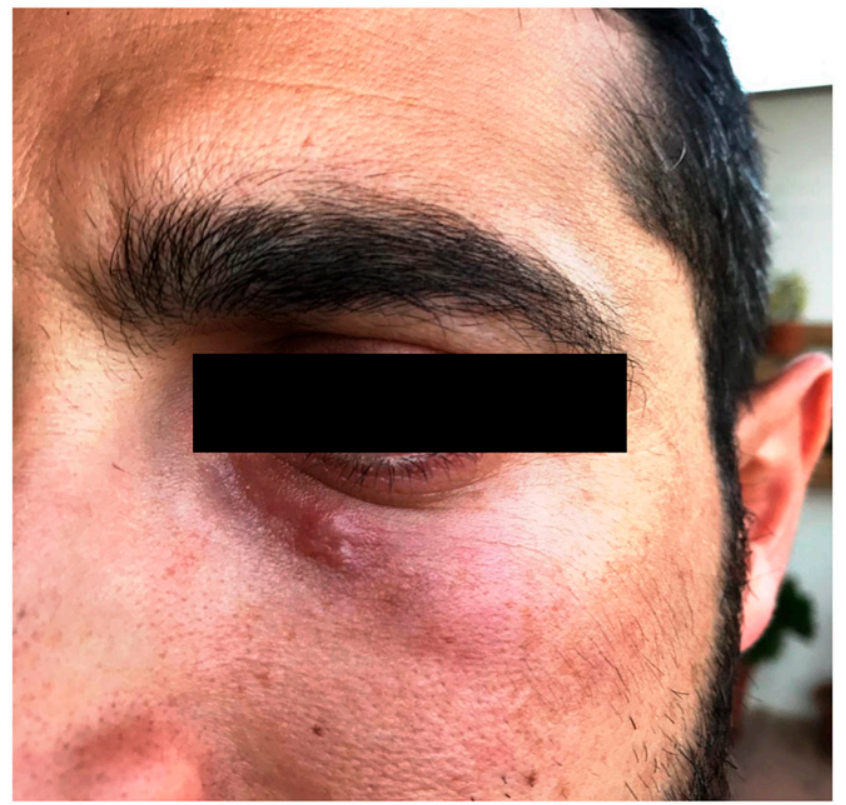

FIGURE 1. The nodule with subpalpebral edema of the patient.

The maximum likelihood phylogeny was inferred by the mean of PhyML 3.0 by applying the generalized time-reversible model, selected by FindModel. The sequence of the isolate was part of a heterogeneous cluster (Supplemental Figure 1) that included sequences from $D$. repens isolated in Germany, Italy, and Croatia, $100 \%$ identical among themselves. Conversely, the sequence from this study was slightly distant $(p$-distance $=$ 0.0015) from them.

After surgical removal of the adult worms, the patient was treated with doxycycline, and no resurgence was reported after one year.

TABLE 1

Hematologic parameters of the patient

\begin{tabular}{lcc}
\hline Hematologic parameter & Value & Normality range \\
\hline Red blood cell count & $5.10 \times 10^{12} / \mathrm{L}$ & $(4.50-5.90) \times 10^{12} / \mathrm{L}$ \\
Hemoglobin & $162 \mathrm{~g} / \mathrm{L}$ & $(135-170) \mathrm{g} / \mathrm{L}$ \\
Hematocrit & $46.4 \%$ & $(41.0-53.0) \%$ \\
Mean cell volume & $90.7 \times 10^{-15} \mathrm{~L}$ & $(80.0-99.0) \times 10^{-15} \mathrm{~L}$ \\
Mean cell hemoglobin & $31.5 \times 10^{-12} \mathrm{~g}$ & $(27.0-24.0) \times 10^{-12} \mathrm{~g}$ \\
Mean cell hemoglobin & $349 \mathrm{~g} / \mathrm{L}$ & $(310-360) \mathrm{g} / \mathrm{L}$ \\
$\quad$ concentration & $12.9 \%$ & $(11.0-15.0) \%$ \\
Red cell distribution & & \\
$\quad$ width & $7.99 \times 10^{9} / \mathrm{L}$ & $(4.5-10.5) \times 10^{9} / \mathrm{L}$ \\
White blood cell count & $5.71 \times 10^{9} / \mathrm{L}$ & $(1.9-8.0) \times 10^{9} / \mathrm{L}$ \\
Neutrophils & $71.42 \%$ & $(38.00-71.00) \%$ \\
& $0.08 \times 10^{9} / \mathrm{L}$ & $\leq 0.06 \times 10^{9} / \mathrm{L}$ \\
Eosinophils & $0.96 \%$ & $\leq 6.00 \%$ \\
Basophils & $0.04 \times 10^{9} / \mathrm{L}$ & $\leq 0.02 \times 10^{9} / \mathrm{L}$ \\
& $0.44 \%$ & $\leq 1.50 \%$ \\
Lymphocytes & $1.58 \times 10^{9} / \mathrm{L}$ & $(1.0-5.2) \times 10^{9} / \mathrm{L}$ \\
Monocytes & $19.80 \%$ & $20.00-50.00 \%$ \\
Platelet count & $0.59 \times 10^{9} / \mathrm{L}$ & $(0.2-1.0) \times 10^{9} / \mathrm{L}$ \\
Mean platelet volume & $7.35 \%$ & $4.00-10.00 \%$ \\
Platelet distribution & $250 \times 10^{9} / \mathrm{L}$ & $(150-350) \times 10^{9} / \mathrm{L}$ \\
width & $9.2 \times 10^{-15} \mathrm{~L}$ & $(7.00-12.50) \times 10^{9} / \mathrm{L}$ \\
Total lgE & $16.7 \%$ & $(10.0-65.0) \%$ \\
\hline
\end{tabular}

\section{DISCUSSION}

The diagnosis of human dirofilariasis mostly relies on the morphologic identification of the worm after biopsy or surgical removal. ${ }^{2}$ Preventive analyses such as ultrasound examinations or pan-filarial lgG tests might be useful to better address surgery, but they cannot provide a definite diagnosis before the morphometric inspection. The currently available ELISA test may be relatively beneficial, but it lacks specificity as it may detect IgG produced after infestation by several species, such as Brugia malayi, Loa loa, Mansonella sp., Onchocerca volvulus, and Wuchereria bancrofti, other than Dirofilaria immitis and $D$. repens. ${ }^{16}$ On the other side, morphologic identification may be time- and labor-consuming, and it requires operators with specific expertise, not always available in all diagnostic laboratories. Nevertheless, the here reported case also poses a matter of sensitivity. Molecular assays managed to detect and identify $D$. repens DNA from the patient's blood, but no microfilariae, or even L3 larvae, were observed by the Knott's test, as expected because of the infrequency of microfilaremia in humans. ${ }^{13}$ In addition, the case evidenced the absence of potential hematological markers for dirofilariasis because no parameter was significantly out of range. The absence of eosinophilia and the low level of $\operatorname{lgE}$, along with the negative results gathered by the IgG-detecting ELISA, reflect the poor efficacy of hematologic or serological diagnostic tools, already known. ${ }^{20}$ Conversely, the case highlights the possible interest of molecular tools due to their sensitivity and specificity, already proved in vitro and, less frequently, infield. It is tempting to speculate that, in humans, the circulation of larval stages of $D$. repens in the patient's blood occurs at very low concentration, insomuch that it can be detectable only by highly sensitive methods, such as the molecular ones. Further studies might be aimed to clearly ascertain which stages are vesiculated by the bloodstream and their concentration.

The value of molecular tests is also enhanced by its potential contribution to the differential diagnosis between loiasis and dirofilariasis, especially for those patients declaring stays in tropical regions considered endemic for $L$. loa. The latter infestation has usually worse outcomes than dirofilariasis, but it is often (but not always) associated with eosinophilia. $^{21}$ In fact, despite uncommon, periocular localization of L. loa has been reported. ${ }^{22}$

Finally, the present report adds further considerations about the possibility to import cases of dirofilariasis from Africa. The infestation has already been diagnosed in patients returning from Malaysia and Botswana to Spain ${ }^{23}$ or from Senegal to France $^{24}$ and Belgium (the latter case with the evidence of microfilaremia), ${ }^{25}$ but no clear pieces of evidence were provided about the acquisition of the infection in foreign countries. Unfortunately, to date, no sequences of $D$. repens collected from Central and Southern Africa are available for comparison, despite it being isolated or detected from dogs in Tanzania $^{26}$ and Cape Verde. ${ }^{27}$ Despite the scarce clonality of $D$. repens population, they could offer very useful information about the worldwide circulation of the parasite, and a potential starting point to assess the international transmission routes, which could be directed to, or even originating from, Europe. 

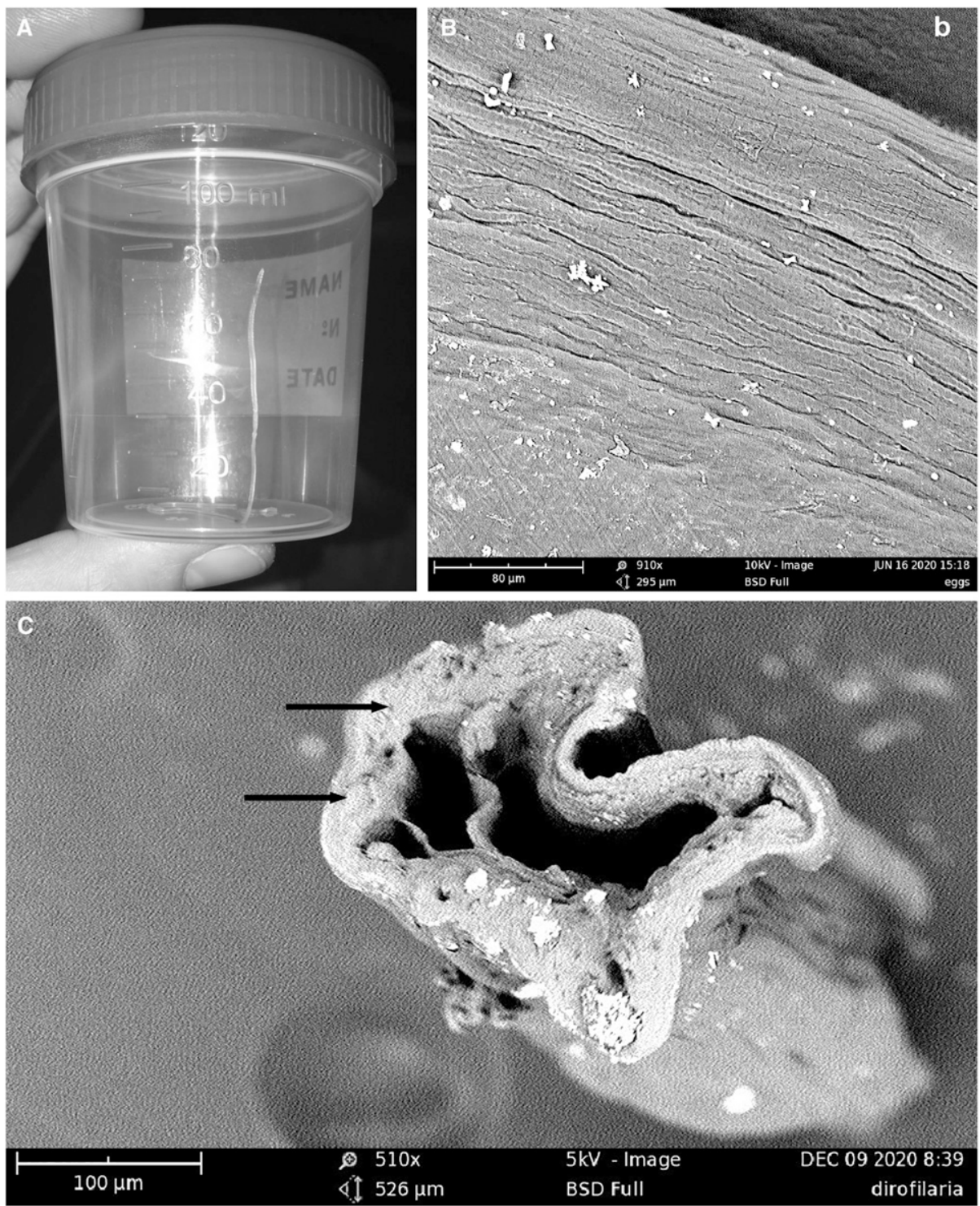

FIGURE 2. (A) Adult worm surgically collected from the nodule. (B) A particular of the SEM micrography evidencing the longitudinal ridges typical of Dirofilaria repens. (C) SEM micrography of a section of the adult worm excised from the patient. Lateral chords are indicated by arrows.

Received October 16, 2020. Accepted for publication January 24, 2021.

Published online May 3, 2021.

Note: Supplemental figure and table appear at www.ajtmh.org.

Acknowledgments: The research was supported by a research grant "Ricerca Corrente: RC01.2018IZSPB" from the Ministry of Health, Italy. The funders had no role in study design, data collection and analysis, decision to publish or preparation of manuscript.

Financial support: The study was funded with own resources, and no specific funds were received.

Authors' addresses: Donato Antonio Raele, Gianfranco La Bella, Ilaria Vasco, Giovanna La Salandra, and Maria Assunta Cafiero, Istituto Zooprofilattico Sperimentale della Puglia e della Basilicata, Foggia, Italy, E-mails: donatoantonio.raele@izspb.it, gianfranco.labella@ izspb.it, ilaria.vasco@izspb.it, giovanna.lasalandra@izspb.it, and mariaassunta.cafiero@izspb.it. Nicola Pugliese, Dipartimento di Medicina Veterinaria, Università degli Studi di Bari, Valenzano, Italy, E-mail: nicola.pugliese@uniba.it. Agata Calvario, Laboratorio di Virologia U.O.C. Microbiologia e Virologia AOU Policlinico, Bari, Italy,
E-mail: agata58calvario@gmail.com. Maria Scarasciulli, Laboratorio di Virologia U.O.C. Microbiologia e Virologia, Dipartimento Interdisciplinare di Medicina, Università degli Studi di Bari, Valenzano, Italy, E-mail: maria.scarasciulli@uniba.it.

This is an open-access article distributed under the terms of the Creative Commons Attribution (CC-BY) License, which permits unrestricted use, distribution, and reproduction in any medium, provided the original author and source are credited.

\section{REFERENCES}

1. Genchi C, Kramer LH, Rivasi F, 2011. Dirofilarial infections in Europe. Vector Borne Zoonotic Dis 11: 1307-1317.

2. Pampiglione $S$, Rivasi $F$, Angeli G, Boldorini R, Incensati RM, Pastormerlo M, Pavesi M, Ramponi A, 2001. Dirofilariasisdue to Dirofilaria repens in Italy, an emergent zoonosis: report of 60 new cases. Histopathol 38: 344-354.

3. Genchi C, Kramer LH, 2020. The prevalence of Dirofilaria immitis and Dirofilaria repens in the Old World. Vet Parasitol 280: 108995.

4. Capelli $G$ et al., 2018. Recent advances on Dirofilaria repens in dogs and humans in Europe. Parasit Vectors 11: 663. 
5. Kartashev V, Afonin A, González-Miguel J, Sepúlveda R, Simón L, Morchón R, Simón F, 2014. Regional warming and emerging vector-borne zoonotic dirofilariosis in the Russian Federation, Ukraine, and other post-Soviet states from 1981 to 2011 and projection by 2030. Biomed Res Int 2014: 858936.

6. Giangaspero A, Marangi M, Latrofa MS, Martinelli D, Traversa D, Otranto D, Genchi C, 2013. Evidences of increasing risk of dirofilarioses in southern Italy. Parasitol Res 112: 1357-1361.

7. Di Cesare A, Otranto D, Di Giulio E, Simonato G, Latrofa MS, La Torre F, Coccia G, Traversa D, 2013. Microfilarial periodicity of Dirofilaria repens in naturally infested dogs. Parasitol Res 112: 4273-4279.

8. Genchi C, Kramer LH, 2017. Subcutaneous dirofilariosis (Dirofilaria repens): an infection spreading throughout the old world. Parasit Vectors 10: 517.

9. Knott J, 1939. A method for making microfilarial surveys on day blood. Trans R Soc Trop Med Hyg 2: 191-196.

10. Traversa D, Di Cesare A, Conboy G, 2010. Canine and feline cardiopulmonary parasitic nematodes in Europe: emerging and underestimated. Parasit Vectors 3: 62.

11. Latrofa MS, Weigl S, Dantas-Torres F, Annoscia G, Traversa D, Brianti E, Otranto D, 2012. A multiplex PCR for the simultaneous detection of species of filarioids infesting dogs. Acta Trop 122: 150-154.

12. Raele DA, Pugliese N, Galante D, Latorre LM, Cafiero MA, 2016. Development and application of a loop-mediated isothermal amplification (LAMP) approach for the rapid detection of Dirofilaria repens from biological samples. PLoS Negl Trop Dis 10: e0004789.

13. Lechner AM, Gastager H, Kern JM, Wagner B, Tappe D, 2020. Case report: successful treatment of a patient with microfilaremic dirofilariasis using doxycycline. Am J Trop Med Hyg 102: 844-846.

14. Fontanelli Sulekova L, Gabrielli S, De Angelis M, Milardi GL, Magnani C, Di Marco B, Taliani G, Cancrini G, 2016. Dirofilaria repens microfilariae from a human node fine-needle aspirate: a case report. J Infect Public Health 9: 102-104.

15. Sabūnas V, Radzijevskaja J, Sakalauskas P, Petkevičius S, Karvelienè B, Žiliukienè J, Lipatova I, Paulauskas A, 2019. Dirofilaria repens in dogs and humans in Lithuania. Parasit Vectors 12: 177 .
16. Gueglio B, Bordier C, Marjolet M, 1995. Mise au point d'un test Elisa pour le diagnostic des filarioses humaines. Bull Soc Fr Parasitol 13: 67-72.

17. Albanese $F$ et al., 2013.Nodular lesions due to infestation by Dirofilaria repens in dogs from Italy. Vet Dermatol 24: 255-e56.

18. To KK et al., 2012. A novel Dirofilaria species causing human and canine infections in Hong Kong. J Clin Microbiol 50: 3534-3541.

19. Beaver PC, Wolfson JS, Waldron MA, Swartz MN, Evans GW, Adler J, 1987. Dirofilaria ursi-like parasites acquired by humans in the Northern United States and Canada: report of two cases and brief review. Am J Trop Med Hyg 37: 357-362.

20. Jelinek T, Schulte-Hillen J, Löscher T, 1996. Human dirofilariasis. Int J Dermatol 35: 872-875.

21. Gobbi F, Tamarozzi F, Buonfrate D, Rodari P, Tais S, Bisoffi Z. 2019. Laboratory parameters after treatment for Loa loa and Mansonella perstans: the experience of a single referral center for tropical siseases in a non-endemic area. Am J Trop Med Hyg 100: 914-920.

22. Bhedasgaonkar S, Baile RB, Nadkarni S, Jakkula G, Gogri P, 2011. Loa loa macrofilariasis in the eyelid: case report of the first periocular subcutaneous manifestation in India. $J$ Parasit Dis 35: 230-231.

23. Laynez-Roldán P, Martínez-de la Puente J, Montalvo T, Mas J, Muñoz J, Figuerola J, Rodriguez-Valero N, 2018. Two cases of subcutaneous dirofilariasis in Barcelona, Spain. Parasitol Res 117: 3679-3681.

24. Argy N, Sabou M, Billing A, Hermsdorff C, Candolfi E, Abou-Bacar A, 2011. A first human case of ocular dirofilariosis due to Dirofilaria repens in Northeastern France. J Trop Med 2011: 698647.

25. Potters I, Vanfraechem G, Bottieau E, 2018. Dirofilaria repens nematode infection with microfilaremia in traveler returning to Belgium from Senegal. Emerg Infect Dis 24: 1671-1673.

26. Mukendi JP, Kimbita E, Mbanzulu KM, Maindo PP, Misinzo G, 2016. Morphological and molecular detection of canine dirofilarial species of veterinary and medical importance in Morogoro municipality, Tanzania. Vet Parasitol 220: 1-3.

27. Marcos R, Pereira C, Maia JP, Santos M, Luzzago C, Lauzi S, Genchi C, Faustino A, Puente-Payo P, 2017. The occurrence of the filarial nematode Dirofilaria repens in canine hosts from Maio Island, Cape Verde. J Helmontol 91: 87-90. 